\title{
PENGARUH NILAI FRACTIONAL ANISOTROPY (DIFFUSION TENSOR IMAGING) PADA TERAPI IMPLANTASI KOKLEA DALAM KLINIS SENSORINEURAL HEARING LOSS (SNHL)
}

\author{
${ }^{1}$ Heny Purnawati, ${ }^{2}$ Mega Amanda, ${ }^{3}$ Vally Wulani, ${ }^{4}$ Eunike Serfina Fajarini \\ 1,2,3 Department of Radiology RSUPN DR Cipto Mangunkusumo Jakarta \\ ${ }^{4} \mathrm{GE}$ Healthcare Indonesia \\ Email: heny.purna@gmail.com
}

\begin{abstract}
Background: Diffusion Tensor Imaging (DTI) on current MRI cochlear examination able to support the diagnosis and help determine implantation therapy. The DTI line can show the cochlea tract and fractional anisotropy (FA) values with reference to the control reference value. DTI can visualize white matter in the cochlear tract that can be mapped in the FA of the entire cochlear image using directions. The FA value on the MRI cochlear examination can be used to determine the continuation of implant placement in the patient by using the FA-DTI value in the case of sensorineural hearing loss (SNHL).

Method: Data were taken from September 2018 to August 2019. The MRI sequences used were Axial T2 $5 \mathrm{~mm}$, Coronal T2 2mm, Axial T2 2mm, Axial 3D Fiesta-C $0.4 \mathrm{~mm}$ and DTI $2 \mathrm{~mm}$. The total time of examination was 20 minutes using post processing Functool on the $2 \mathrm{~mm}$ DTI results, measuring the region of interest (ROI) to obtain FA values in several segments, namely region Trapezoid Body (rTB), region Superior Olivary Nucleus (rSON), region Inferior Colliculus (rIC), region Medial Geniculate (rMG), region Auditory Radiation (rAR).

Result:The results of the DTI image are very sensitive to produce a diagnosis in the form of nerve fibers. DTI which is supported by the results of the FA score is able to provide quantitative information.

Conclusion: There is an effect on the FA-DTI value in SNHL cases for cochlear implant therapy.
\end{abstract}

Keywords: DTI, SNHL, Fractional Anisotropy, Implant, Cochlear

\section{Pendahuluan}

Koklea adalah organ pendengaran berbentuk menyerupai rumah siput dengan dua dan satu setengah putaran pada aksis memiliki panjang lebih kurang 3,5 centimeter. Sentral aksis disebut sebagai modiolus dengan tinggi lebih kurang 5 milimeter, berisi berkas saraf dan suplai arteri dari arteri vertebralis. Dua belas struktur duktus koklea dan ruang periotik sangat kompleks membentuk suatu sistem dengan tiga ruangan yaitu skala vestibuli, sedangkan pars intermedia terdiri dari duktus dan sakus endolimpaticus, skala media dan skala timpani. Skala vestibuli dan skala tympani berisi cairan perilim sedangkan skala media berisi endolimf. Skala vestibuli dan skala media dipisahkan oleh membran reissner, skala media dan skala timpani dipisahkan oleh membran basilar.

Sensorineural Hearing Loss (SNHL) merupakan gangguan pendengaran akibat penurunan fungsi saraf pendengaran. Kondisi ini bisa terjadi pada mereka yang mengalami kelainan genetik, kelainan kongenital misalnya akibat torch saat proses kehamilan dan penurunan pendengaran akibat penuaan. SNHL 
yaitu gangguan pendengaran sensorineural yang disebabkan oleh hilangnya atau rusaknya sel saraf (sel rambut) di dalam rumah siput. Biasanya gangguan ini bersifat permanen. Diagnosis tuli sensorineural dilakukan dengan tes pendengaran. Tes pendengaran (audiometri) dilakukan oleh dokter untuk menentukan tingkat keparahan gangguan pendengaran, serta menentukan apa jenis gangguan pendengaran tersebut apakah konduktif, sensorineural atau kombinasi keduanya.

Setelah tes audiometri, dokter melakukan tes pencitraan MRI. Tes Pencitraan MRI yang dilakukan adalah pemeriksaan MRI Koklea. MRI Koklea merupakan pemeriksaan diagnostik yang harus dilakukan sebelum pemasangan implan. MRI Koklea adalah pencitraan menggunakan mesin MRI, yang mana objek yang diperiksa adalah koklea. Pemeriksaan MRI ini bertujuan untuk menganalisa sel saraf di dalam rumah siput. Nilai FA yang dihasilkan kemudian dijadikan acuan untuk terapi selanjutnya.

Pada penelitian ini, klinis Sensorineural Hearing Loss (SNHL) banyak ditemukan di Departemen Radiologi RSCM. Penulis ingin mengembangkan keilmuan khususnya pada bidang MRI. Dimana radiografer tidak hanya dapat mengerjakan pembuatan citra MRI, namun diharapkan radiografer juga dapat menganalisa suatu data ataupun permasalahan yang ditemukan di lapangan.

\section{Metode}

Penelitian ini menggunakan metode analitik kuantitatif. Data diambil pada September 2018 hingga Agustus 2019. Alat yang digunakan dalam penelitian ini adalah MRI 1.5 Tesla Optima 450w GEM GE Healthcare. Sekuen MRI yang digunakan pada klinis Sensorineural Hearing Loss (SNHL) adalah Axial T2 5mm,
Coronal T2 2mm, Axial T2 2mm, Axial 3D Fiesta-C 0.4mm dan DTI $2 \mathrm{~mm}$.

Ada 20 sampel data dengan rentang usia 015 tahun (8 laki-laki dan 12 perempuan) (Tabel 1). Hasil nilai fractional anisotropy-diffusion tensor imaging (FA-DTI) setelah dilakukan perhitungan region of interest (ROI) pada beberapa segmen dengan aplikasi Functool di post processing software (Advance Workstation/AW) 4.6 version GE System pada klinis SNHL. Beberapa segmen tersebut adalah region Trapezoid Body (rTB), region Superior Olivary Nucleus (rSON), region Inferior Colliculus ( $\mathrm{rCO}$ ), region Medial Geniculate (rMG) dan region Auditory Radiation (rAR).

Analisa data menggunakan SPSS 20 dan Excell 2019 sehingga didapatkan hasil statistik yang sesuai. Hipotesa awal pada penelitian ini (Ho) ada pengaruh dari nilai FA-DTI terhadap terapi implantasi koklea dalam klinis SNHL. Dan (Ha) tidak ada pengaruh dari nilai FA-DTI terhadap terapi implantasi koklea dalam klinis SNHL.

\section{Hasil dan Pembahasan}

Tabel 1. Kelompok umur yang didapat

\begin{tabular}{lcc}
\hline $\begin{array}{c}\text { KELOMPOK } \\
\text { UMUR }\end{array}$ & JUMLAH & PRESENTASE \\
\hline 0-5 Tahun & 15 & $75 \%$ \\
6-10 Tahun & 2 & $10 \%$ \\
11-15 Tahun & 3 & $15 \%$ \\
\hline \multicolumn{1}{c}{ Total } & 20 & $100 \%$ \\
\hline
\end{tabular}

Tabel 2. Kelompok jenis kelamin yang didapat

\begin{tabular}{|c|c|c|}
\hline JENIS KELAMIN & JUMLAH & PRESENTASE \\
\hline Laki-Laki & 12 & $60 \%$ \\
\hline Perempuan & 8 & $40 \%$ \\
\hline Total & 20 & $100 \%$ \\
\hline
\end{tabular}




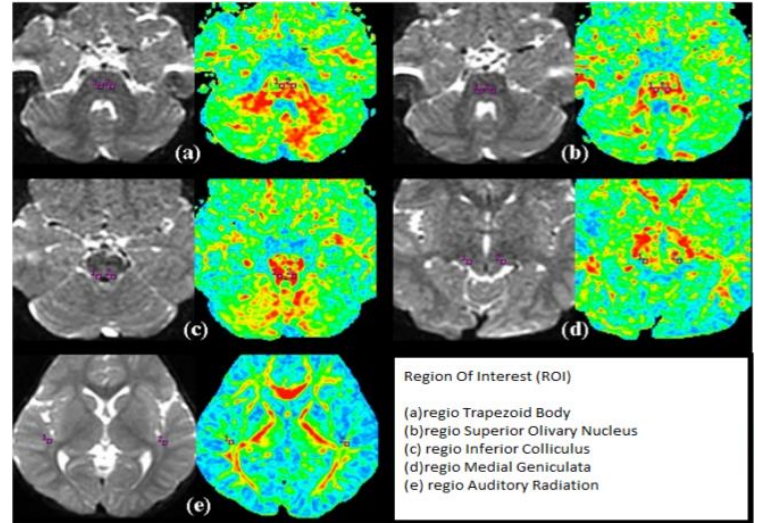

Gambar 1. Region of interest (ROI) pada beberapa segmen dengan aplikasi Functool di post processing

Protokol pemeriksaan MRI Koklea dengan klinis SNHL menggunakan sekuen MRI, Axial T2 5mm, Coronal T2 2mm, Axial T2 2mm, Axial $3 D$ Fiesta-C $0.4 m m$ dan DTI $2 \mathrm{~mm}$.

Sekuen DTI $2 \mathrm{~mm}$ memberikan gambaran fractional anisotropy yang akan diproses lebih lanjut. Hasil nilai fractional anisotropy-diffusion tensor imaging (FA-DTI) setelah dilakukan perhitungan region of interest (ROI) pada beberapa segmen dengan aplikasi Functool di post processing software (Advance Workstation/AW) 4.6 version GE System pada klinis SNHL.

Beberapa segmen tersebut adalah Region Trapezoid Body (rTB), Region Superior Olivary Nucleus (rSON), Region Inferior Colliculus (rCO), Region Medial Geniculate (rMG) dan Region Auditory Radiation (rAR) (Tabel 3 -4).

Analisia data menggunakan Excel 2019, sehingga didapatkan hasil statistik. Hipotesa awal pada penelitian ini (Ho) ada pengaruh dari nilai FA-DTI terhadap terapi implantasi koklea dalam klinis SNHL dan hipotesa akhir (Ha) tidak ada pengaruh dari nilai FA-DTI terhadap terapi implantasi koklea dalam klinis SNHL.

Hasil data yang digunakan dibandingkan dengan nilai kontrol. Untuk perbandingan dalam kelompok SNHL dan kelompok kontrol ${ }^{1}$, digunakan dengan nilai $\mathrm{P}$ dua sisi $<0,05$ dianggap signifikan secara statistik.
Tabel 2. Nilai $r F A$ dari $r T B, r S O N, r C I, r M G, r A R$ pada kelompok SNHL Left.

Nilai Fractional Anisotropy (FA)

\begin{tabular}{|c|c|c|c|c|c|c|c|}
\hline \multirow[t]{2}{*}{$\begin{array}{l}\mathbf{L} / \\
\mathbf{P} \\
\end{array}$} & \multirow[t]{2}{*}{$\begin{array}{l}\text { Um } \\
\text { ur } \\
\end{array}$} & \multirow[t]{2}{*}{$\begin{array}{c}\text { Kas } \\
\text { us } \\
\end{array}$} & $\begin{array}{c}\text { Trape } \\
\text { zoid } \\
\text { Body } \\
\end{array}$ & \multirow{2}{*}{$\begin{array}{c}\begin{array}{c}\text { Supe } \\
\text { rior } \\
\text { Oliv } \\
\text { ary } \\
\text { Nucl } \\
\text { eus }\end{array} \\
\text { Left }\end{array}$} & \multirow{2}{*}{$\begin{array}{c}\begin{array}{c}\text { Inferi } \\
\text { or } \\
\text { Collic } \\
\text { ulus }\end{array} \\
\text { Left }\end{array}$} & \multirow{2}{*}{ 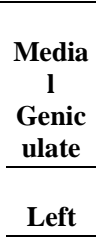 } & \multirow{2}{*}{$\begin{array}{c}\begin{array}{c}\text { Audit } \\
\text { ory } \\
\text { Radia } \\
\text { tion }\end{array} \\
\text { Left }\end{array}$} \\
\hline & & & Left & & & & \\
\hline & & $\begin{array}{c}\text { Mea } \\
n\end{array}$ & $\begin{array}{r}0,413 \\
75\end{array}$ & $\begin{array}{c}0,460 \\
8\end{array}$ & $\begin{array}{c}0,522 \\
35\end{array}$ & 0,3668 & $\begin{array}{c}0,305 \\
75\end{array}$ \\
\hline & & Min & 0,243 & 0,194 & 0,195 & 0,159 & 0,117 \\
\hline & & $\begin{array}{c}\text { Max } \\
\text { Med } \\
\text { ian }\end{array}$ & $\begin{array}{c}0,582 \\
0,412 \\
5\end{array}$ & 0,618 & $\begin{array}{c}0,738 \\
0,466 \\
5\end{array}$ & 0,763 & 0,499 \\
\hline
\end{tabular}

Tabel 3. Nilai $r F A$ dari $r T B, r S O N, r C I, r M G, r A R$ pada kelompok SNHL Right.

Nilai Fractional Anisotropy (FA)

\begin{tabular}{|c|c|c|c|c|c|c|}
\hline \multirow[t]{2}{*}{$\begin{array}{ll}\mathbf{L} & \mathbf{U} \\
l & \mathbf{n} \\
\mathbf{P} & \mathbf{u} \\
& \mathbf{r}\end{array}$} & \multirow[t]{2}{*}{$\begin{array}{l}\text { Klin } \\
\text { is }\end{array}$} & $\begin{array}{l}\text { Trape } \\
\text { zoid } \\
\text { Body }\end{array}$ & $\begin{array}{c}\text { Superi } \\
\text { or } \\
\text { Olivar } \\
\mathbf{y} \\
\text { Nucleu } \\
\mathbf{s}\end{array}$ & $\begin{array}{c}\text { Inferi } \\
\text { or } \\
\text { Collic } \\
\text { ulus }\end{array}$ & $\begin{array}{c}\text { Medial } \\
\text { Genic } \\
\text { ulate }\end{array}$ & $\begin{array}{c}\text { Auditor } \\
\mathbf{y} \\
\text { Radiati } \\
\text { on }\end{array}$ \\
\hline & & Right & Right & Right & Right & Right \\
\hline & $\begin{array}{c}M e a \\
n\end{array}$ & 0,2904 & 0,47085 & $\begin{array}{c}0,5043 \\
5\end{array}$ & $\begin{array}{c}0,3755 \\
5\end{array}$ & 0,322205 \\
\hline & $\operatorname{Min}$ & 0,217 & 0,222 & 0,205 & 0,186 & 0,0861 \\
\hline & $\operatorname{Max}$ & 0,39 & 0,656 & 0,705 & 0,595 & 0,54 \\
\hline & $\begin{array}{c}\text { Med } \\
\text { ian }\end{array}$ & 0,3035 & 0,439 & 0,455 & 0,3905 & 0,31305 \\
\hline
\end{tabular}

Hasil perbandingan nilai $r F A$ dari $r T B$, rSON, $r C I, r M G, r A R$ pada kelompok SNHL terhadap kelompok kontrol.

Dari 20 sampel tersebut diperoleh informasi berupa hasil operasi hitung nilai berdasarkan ROI. Besar area ROI adalah 1mm yang diperoleh dengan menggunakan post processing functool.

Hasil gambaran DTI sangat sensitif untuk menghasilkan diagnosa berupa serabut syaraf. 
DTI yang ditunjang dengan hasil nilai FA mampu memberikan informasi kuantitatif

Tabel 4. Perbandingan nilai kontrol dengan nilai kelompok data.

$$
\text { SNHL }(\mathrm{n}=20) \quad \text { Kontrol }(\mathrm{n}=20) \quad P \text {-value }
$$

\begin{tabular}{llll}
\hline rTB & $0.43 \pm 0.02$ & $0.39 \pm 0.02$ & $0.011^{*}$ \\
rSON & $0.63 \pm 0.02$ & $0.38 \pm 0.01$ & $0.016^{*}$ \\
rCI & $0.72 \pm 0.02$ & $0.46 \pm 0.02$ & $0.012^{*}$ \\
rMG & $0.64 \pm 0.03$ & $0.36 \pm 0.01$ & $0.017^{*}$ \\
rAR & $0.51 \pm 0.01$ & $0.38 \pm 0.03$ & $0.013^{*}$
\end{tabular}

untuk mempengaruhi terapi implantasi koklea. Nilai p-value yang didapat berdasarkan hasil perbandingan nilai kontrol dengan niai kelompok data.

\section{Simpulan}

Dari hasil penelitian ada pengaruh nilai FA-DTI terhadap terapi implantasi koklea dalam klinis SNHL (Ho).

\section{Daftar Pustaka}

Lexing Huang, Wenbin Zheng,,Chunxiao Wu, Xiaoqin Wei, Xianguang Wu, Yanting Wang, and Hongyi Zheng, Juan Zhou, Editor Diffusion Tensor Imaging of the Auditory Neural Pathway for Clinical Outcome of Cochlear Implantation in Pediatric Congenital Sensorineural Hearing Loss Patients. https://www.ncbi.nlm.nih.gov/pmc/articles/P MC4618518/

American Speech-Languge-Hearing Association. Effect of Hearing Loss on Development. Rockville, United State of America; 2015

Chang Y, Lee HR, Paik JS, Lee KY, Lee SH. Voxelwise analysis of diffusion tensor imaging for clinical outcome of cochlear implantation: retrospective study. Clin Exp Otorhinolaryngol 2012; 5 Suppl 1:S37-42. 10.3342/ceo.2012.5.S1.S37
Hong P, Jurkowski ZC, Carvalho DS. Preoperative cerebral magnetic resonance imaging and white matter changes in pediatric cochlear implant recipients. Int $\mathrm{J}$ Pediatr Otorhinolaryngol 2010; 74(6):658-60. 10.1016/j.ijporl.2010.03.014

Jonas NE, Ahmed J, Grainger J, Jephson CG, Wyatt ME, Hartley BE, et al. MRI brain abnormalities in cochlear implant candidates: how common and how important are they? Int J Pediatr Otorhinolaryngol 2012; 76(7):9279. 10.1016/j.ijporl.2012.02.070

Joshi VM, Navlekar SK, Kishore GR, Reddy KJ, Kumar EC. CT and MR Imaging of the inner ear and brain in children with congenital sensorineural hearing loss. Radiographics 2012; 32(3):683-698. 10.1148/rg.323115073

Lazard DS, Lee HJ, Truy E, Giraud AL. Bilateral reorganization of posterior temporal cortices in post-lingual deafness and its relation to cochlear implant outcome. Hum Brain Mapp 2013; 34(5):1208-19. 10.1002/hbm.21504

Licameli G, Kenna MA. Is computed tomography (CT) or magnetic resonance imaging (MRI) more useful in the evaluation of pediatric sensorineural hearing loss?. Laryngoscope 2010; 120(12):2358-2359. 10.1002/lary.21363

Moon IJ, Kim EY, Park GY, Jang MS, Kim JH, Lee $\mathrm{J}$, et al. The clinical significance of preoperative brain magnetic resonance imaging in pediatric cochlear implant recipients. Audiol Neurootol 2012; 17(6):373-80. 10.1159/000341818 